\title{
Development and evaluation of two TaqMan assays for generic detection of Dickeya species
}

\author{
Carolien Zijlstra • Lia Groenenboom - De Haas • \\ Marjon Krijger • Els Verstappen • Sven Warris • \\ Eisse de Haan - Jan van der Wolf
}

Accepted: 17 October 2019 /Published online: 22 November 2019

(C) The Author(s) 2019 many if not all can cause plant diseases. In 2005, D. chrysanthemi, D. dadantii, D. dianthicola, D. paradisiaca, D. solani and D. zeae were described as species (Samson et al. 2005). More recently D. aquatica D. fongzhangdai and D. lacustris were described (Parkinson et al. 2014; Tian et al. 2016; HugouvieuxCotte-Pattat et al. 2019). From the various Dickeya species, $D$. dianthicola, $D$. dadantii and $D$. solani have been described as causative agents of potato blackleg (Czajkowski et al. 2011, Toth et al. 2011). For detection of the pathogen, various Dickeya species-specific TaqMan assays have been developed, such as for D. solani and D. dianthicola (Pritchard et al. 2013, van der Wolf et al. 2014), D. dadantii, D. paradisiaca, $D$. chrysanthemi, D. zeae and D. dieffenbachiae (van der Wolf et al. 2014). However, detection of multiple species with individual assays in large-scale testing programs is laborious and expensive. There is obviously a need for assays that enable faster and more costeffective testing of seed lots. In 1996, a conventional PCR assay for the generic detection of all Dickeya species was developed (Nassar et al. 1996). Combined with an enrichment step to increase densities of Dickeya species in plant extracts, this PCR test seemed to be suitable as a tool in a disease management program (Tsror et al. 2012). However, conventional PCR assays require the use of gel electrophoresis as a post amplification step to analyse the amplicons, which make the assays less suitable for high throughput screening. Because TaqMan assays involve fluorescence measurements that can be performed without opening the PCR tube, the risk of carry-over product is greatly reduced

E. de Haan

NAK, Randweg, 14 Emmeloord, Netherlands 
(Kalinia et al. 1997). Moreover, the use of a fluorescent probe in TaqMan assays allows real time measurements which reduces labour costs and increases specificity. The aim of this study was to develop a TaqMan assay that detects all Dickeya species that can affect potato, i.e. $D$. dadantii, D. dianthicola and D. solani, but not (related) non-target bacteria, and that can be successfully applied for testing of potato tissues for blacklegcausing Dickeya species.

In order to design primers and probes that detect all known species of Dickeya present on potato in Europe, they need to be conserved in Dickeya, but they should not be found in non-target organisms. To find these conserved regions, the genome of a D. solani strain (IPO2222) was selected as the reference as it consisted of a single $4.9 \mathrm{Mb}$ contig (Khayi et al., 2016). This reference sequence was split up in $500 \mathrm{bp}$ fragments, resulting in 9898 sequences (set A). After mapping the sequences from set A with BWA MEM (Li, 2013) to D. chrysanthemi, D. dadantii, D. dianthicola, D. dieffenbachiae, D. solani and D. zeae, sequences aligning to all genomes were selected (conserved set B). Sequences from set B mapping to Pectobacterium atroseptica, P. brasiliensis, $P$. carotovorum, $P$. odoriferum, $P$. betavasculorum and $P$. wasabiae were discarded. The remaining conserved 500 bp regions (set $\mathrm{C}$ ) were sorted based on the number of mismatches within the group of blackleg-causing Dickeya species.

Two sets of primers and probes for the TaqMan PCRs for generic detection of all Dickeya species were designed on the basis of the selected conserved regions (set C) in Dickeya using Primer Express 3.0 (Applied Biosystems). The MGB TaqMan probes were labelled with a $5^{\prime}$-end reporter dye (FAM-6-carboxyfluorescein (FAM) ) and a 3'-end quencher dye (BHQ-1). The first set was derived from a gene encoding a ferrodoxin subunit involved in aerobic respiration. It consisted of forward primer Fw109 (5'-GCGCGCAGCACTHGAT$\left.3^{\prime}\right), \mathrm{H}=\mathrm{A}$ or $\mathrm{C}$ or $\mathrm{T}$; reverse primer Rv109 (5'CGACGGCACGCTCAGAAT-3') and probe P109 (5'AAGCCGCGGAAAT-3'). The other set was derived from a potassium transporter Kup involved in potassium-ion uptake under hyper osmotic stress at a low pH. It consisted of forward primer Fw284 (5'TGTGCGTTTTCGGGCTASTC-3'), S=C or G; reverse primer Rv284 (CCYTGTCTTCTGTTATCAATTCAT TAAC- $\left.3^{\prime}\right), Y=C$ or $\mathrm{T}$ and probe $\mathrm{P} 284$ (5' -
AACCAGAATAAGGCCC-3'). DNA was isolated from bacterial strains listed in Table S1. DNA was extracted from pure cultures of bacteria grown for $48 \mathrm{~h}$ on TSA at $27{ }^{\circ} \mathrm{C}$. The bacteria were scraped from the agar surface and stored at $-20{ }^{\circ} \mathrm{C}$ until DNA extraction. The DNA was extracted using the Wizard Magnetic DNA purification System for Food (Promega, Leiden, The Netherlands). DNA yield was determined by fluorescence using the Pico ${ }^{\circledR}$ Green I dye (Invitrogen) and a TECAN Infinite ${ }^{\circledR}$ M200 pro microplate reader (Tecan Group Ltd., Switzerland). The selected primer sets and corresponding probes were tested in TaqMan assays performed in a 96-well format in an ABI Prism 7500 apparatus. For each TaqMan assay, $2 \mu$ sample was mixed with $23 \mu$ reaction mix containing $12.5 \mu \mathrm{l}$ 2X Premix Ex Taq (Takara Bio Inc. Otsu, Shiga, Japan), $0.5 \mu$ l 50X ROX reference Dye II (Takara Bio Inc.), $100 \mathrm{nM}$ probe and $300 \mathrm{nM}$ of each forward and reverse primer. The reaction conditions were: an initial incubation step at $50{ }^{\circ} \mathrm{C}$ for $2 \mathrm{~min}$; $95{ }^{\circ} \mathrm{C}$ for $10 \mathrm{~min} ; 40$ cycles of $95{ }^{\circ} \mathrm{C}$ for $15 \mathrm{~s}$ followed by $60{ }^{\circ} \mathrm{C}$ for $60 \mathrm{~s}$. Analysis of the data was done by automatic threshold calculation within the 7500 system software version 1.2.3. Ct-values were interpreted qualitatively. Reactions with $\mathrm{Ct}-$ values below 35 were considered positive.

The specificity of the generic Dickeya TaqMan assays was evaluated using $0.4 \mathrm{ng}$ DNA of pure cultures of target and non-target strains. Results are summarized in Table 1 and full results are shown in Table S1. All 36 strains of the 6 target species, i.e. D. chrysanthemi, $D$. dadantii, $D$. dianthicola, $D$. dieffenbachia, D. solani and $D$. zeae, were detected by both TaqMan assays. TaqMan reactions of the 77 strains of more than 15 non-target species tested were all negative. In general, Ct-values of both assays were similar. Ct-values of the tested strains of D. chrysanthemi, D. dadantii, D. dianthicola, D. dieffenbachia, D. solani and D. zeae varied between 15.4 and 23.2 when TaqMan set 109 was used and between 15.8 and 24.2 for TaqMan set 284. However, Ct-values of the D. paradisiaca strains were higher and varied between 29.3 and 36.0. Three out of four strains of D. paradisiaca were positive when TaqMan assay set 109 was used and two out of four were positive when TaqMan set 284 was used. None of the 77 non-target strains were positive, including 61 strains of various taxonomically related Pectobacterium species. 
Table 1 Results of TaqMan assays (with set 109 and set 284), developed for generic detection of Dickeya species, with target and non-target bacteria

\begin{tabular}{|c|c|c|c|c|}
\hline & & \multirow[t]{2}{*}{ Numbers of strains tested } & \multicolumn{2}{|c|}{ Numbers of strains positive $(\mathrm{Ct}<35)^{1}$} \\
\hline & & & Set 109 & Set 284 \\
\hline \multirow[t]{6}{*}{ Target bacteria } & D. chrysanthemi & 4 & 4 & 4 \\
\hline & D. dadantii & 6 & 6 & 6 \\
\hline & D. dianthicola & 11 & 11 & 11 \\
\hline & D. solani & 6 & 6 & 6 \\
\hline & D zeae & 7 & 7 & 7 \\
\hline & D. paradisiaca & 4 & $3^{2}$ & $2^{2}$ \\
\hline \multirow[t]{3}{*}{ Non-target bacteria } & Pectobacterium sp. & 61 & 0 & 0 \\
\hline & Other bacteria & 14 & 0 & 0 \\
\hline & Water control & 2 & 0 & 0 \\
\hline
\end{tabular}

TaqMan assays 109 and 284 were highly specific and detected all plant pathogenic Dickeya species involved in the studies, with the exception of D. paradisiaca for which relatively high $\mathrm{Ct}$-values were found. Also in other studies, $D$. paradisiaca was found divergent from the other Dickeya species (Naushad et al. 2014). This pathogen has a narrow host range, being isolated only from Musa species and Zea mays that were grown in tropical regions. It has never been described in association with potato.

The TaqMan assays were further evaluated using ten lots of seed potatoes from different places in the Netherlands and belonging to different cultivars, i.e. Amorosa (Groningen), Binella (Zeeland), Diamant E (Groningen), Elmundo (Noord Holland), Fabula E (Noordoostpolder), Kondor (Zeeland), Monalisa A (Friesland), Monalisa (Friesland), Picasso A (Noord Holland) and Zafira A (Noordoostpolder). From the same ten seed lots regular (commodity) samples were collected as done by seed inspectors, as well as samples of refused tubers that do not meet the quality standards. The refused tubers showed bruises, were misshaped and/or showed decay. We hypothesized that Dickeya would be more readily detected in refused samples. Two times ten subsamples of 20 tubers per seed lot were analysed, ten subsamples for the commodity samples and ten subsamples for the regular samples per seed lot. These 20 tubers from each subsample were put in $100 \mu \mathrm{m}$ thick bags (Topa, Lelystad) and $5 \mathrm{ml}$ water was added. The bags were vacuumed and incubated for
7 days at room temperature. Subsequently $1 \mathrm{ml}$ of the rotten extract was used for DNA extraction using the Wizard Magnetic DNA purification System for Food (Promega, Leiden, The Netherlands). One hundred regular potato subsamples and 97 refused potato subsamples were analysed with the TaqMan assays 109 and 284 for generic detection of Dickeya species with TaqMan assays 109 and 284.

Full results are shown in Table S2 and results are summarized in Table 2. Of 100 regular subsamples 90 subsamples were negative and four subsamples were positive for the presence of Dickeya species by both generic assays (Set 109 and Set 284). Four subsamples were positive with Set 109 and negative for set 284. Conversely, two subsamples were positive with set 284 and negative with set 109 . Ctvalues of the positive regular subsamples were relatively high (between 30 and 35) except for a highly positive sample of Elmundo with Ct-values of 17.0 and 17.7 for set 284 and set 109 respectively. Of the 97 refused subsamples, $82(84.5 \%)$ were tested negative for the presence of Dickeya species by both generic TaqMan assays. Thirteen subsamples $(13.4 \%)$ were tested positive by both generic assays. Two subsamples $(2.1 \%)$ were positive with set 109 and negative with set 284 .

The sensitivity, specificity and accuracy of both assays are summarized in Table 3. Results of both assays are similar and the calculated values of the selected characteristics are high. With set 284 there was a lower number of subsamples positive, which 
Table 2 Evaluation of TaqMan assays for detection of plant pathogenic Dickeya species with potato tubers collected from seed lots

\begin{tabular}{|c|c|c|c|c|c|c|c|c|}
\hline \multirow[b]{2}{*}{ Seed lot } & \multirow[b]{2}{*}{ Type } & \multirow[b]{2}{*}{ Nr. of subsamples } & \multicolumn{2}{|c|}{$\begin{array}{l}\text { Numbers of positive } \\
\text { subsamples }(\mathrm{Ct}<35) \text { in } \\
\text { TaqMan assay: }\end{array}$} & \multirow[b]{2}{*}{ Type } & \multirow[b]{2}{*}{ Nr. of subsamples } & \multicolumn{2}{|c|}{$\begin{array}{l}\text { Numbers of positive } \\
\text { subsamples }(\mathrm{Ct}<35) \text { in } \\
\text { TaqMan assay: }\end{array}$} \\
\hline & & & Set $109^{1}$ & Set $284^{1}$ & & & Set 109 & Set 284 \\
\hline Zafira A & Regular $^{2}$ & 10 & $1^{3}$ & 0 & Refused $^{4}$ & 10 & 0 & 0 \\
\hline Fabula E & Regular & 10 & 1 & 0 & Refused & 10 & 7 & 6 \\
\hline Monalisa A & Regular & 10 & 1 & 0 & Refused & 10 & 0 & 0 \\
\hline Diamant E & Regular & 10 & 0 & 0 & Refused & 10 & 0 & 0 \\
\hline Amorosa & Regular & 10 & 1 & 0 & Refused & 9 & 3 & 2 \\
\hline Elmundo & Regular & 10 & 1 & 1 & Refused & 10 & 3 & 3 \\
\hline Picasso A & Regular & 10 & 0 & 0 & Refused & 8 & 2 & 2 \\
\hline Monalisa & Regular & 10 & 3 & 3 & Refused & 10 & 0 & 0 \\
\hline Binella & Regular & 10 & 0 & 1 & Refused & 10 & 0 & 0 \\
\hline \multirow[t]{2}{*}{ Kondor } & Regular & 10 & 0 & 1 & Refused & 10 & 0 & 0 \\
\hline & Total & 100 & 8 & 6 & Total & 97 & 15 & 13 \\
\hline
\end{tabular}

\footnotetext{
${ }^{1}$ Set 109 and Set 284 were developed in this study for detection of plant pathogenic Dickeya species

${ }^{2}$ Subsamples of a regular seed lot consisted of 20 tubers as collected by NAK inspector

${ }^{3} \mathrm{Ct}$-values of positive regular samples were relatively high (between 30 and 35), except for the single positive sample of Elmundo (17.0 and 17.7)

${ }^{4}$ Refused samples, tubers that did not meet quality standards (misshaped, damaged, or diseased tubers)
}

may be a disadvantage if the generic assay is used for initial screening. In the refused samples more Dickeya was found than in the regular samples (Table 2) which confirmed our hypothesis that Dickeya is more frequently present in rejected tubers that are misshaped, wounded or rotten.

In order to determine the detection ranges of the Dickeya TaqMan assays in a background of potato extract, 10-fold dilution series (10 fg - $10 \mathrm{ng})$ of genomic DNA of D. solani strain IPO 2187 were prepared in a background of ca. $34 \mathrm{ng}$ of DNA extracted from potato extract from regular tubers tested negative for the presence of Dickeya. When set 109 was used, the response was linear with a slope of -3.29 , an $\mathrm{R}^{2}$ of 0.996 and a Y-intercept of 39.0 (Fig.1A). The response was also linear when set 284 was used (Fig. 1B) with a slope of -3.58 , an $\mathrm{R}^{2}$ of 0.975 and a Y-intercept of 41.5 .

Table 3 Characteristics of the TaqMan assays for generic detection of Dickeya species in potato seed lots

\begin{tabular}{lll}
\hline Definition & Formula $^{1}$ & ${\text { Value }(\%)^{2}}^{2}$ \\
\hline Set 284 as reference for set 109 & & 89 \\
Sensitivity of set 109 & $\mathrm{TP} /(\mathrm{TP}+\mathrm{FN})$ & 97 \\
Specificity of set 109 & $\mathrm{TN} /(\mathrm{TN}+\mathrm{FP})$ & 96 \\
Accuracy of set 109 & $(\mathrm{TN}+\mathrm{TP}) /(\mathrm{TN}+\mathrm{TP}+\mathrm{FN}+\mathrm{FP})$ & 74 \\
Set 109 as reference for set 284 & $\mathrm{TP} /(\mathrm{TP}+\mathrm{FN})$ & 99 \\
Sensitivity of set 284 & $\mathrm{TN} /(\mathrm{TN}+\mathrm{FP})$ & 96 \\
Specificity of set 284 & $(\mathrm{TN}+\mathrm{TP}) /(\mathrm{TN}+\mathrm{TP}+\mathrm{FN}+\mathrm{FP})$ & \\
Accuracy of set 284 &
\end{tabular}

\footnotetext{
${ }^{1} \mathrm{TP}=$ True positive, $\mathrm{FP}=$ False positive, $\mathrm{TN}=$ True Negative, $\mathrm{FN}=$ False Negative

${ }^{2} 197$ subsamples of seed potatoes were analysed with two TaqMan assays for the presence of Dickeya species. Ct-values $<35$ were considered positive
} 
Fig. 1 Standard curves showing the relationship between $\mathrm{Ct}$ (cycle threshold) and quantity of genomic DNA of Dickeya solani strain IPO 2187 in a background of DNA from potato extract using the generic Dickeya TaqMan assays. (A) Ct-values for set 109 plotted against the quantity (log base 10) of Dickeya DNA (fg). (B) Ct-values for set 284 plotted against the quantity (log base 10) of Dickeya DNA (fg)
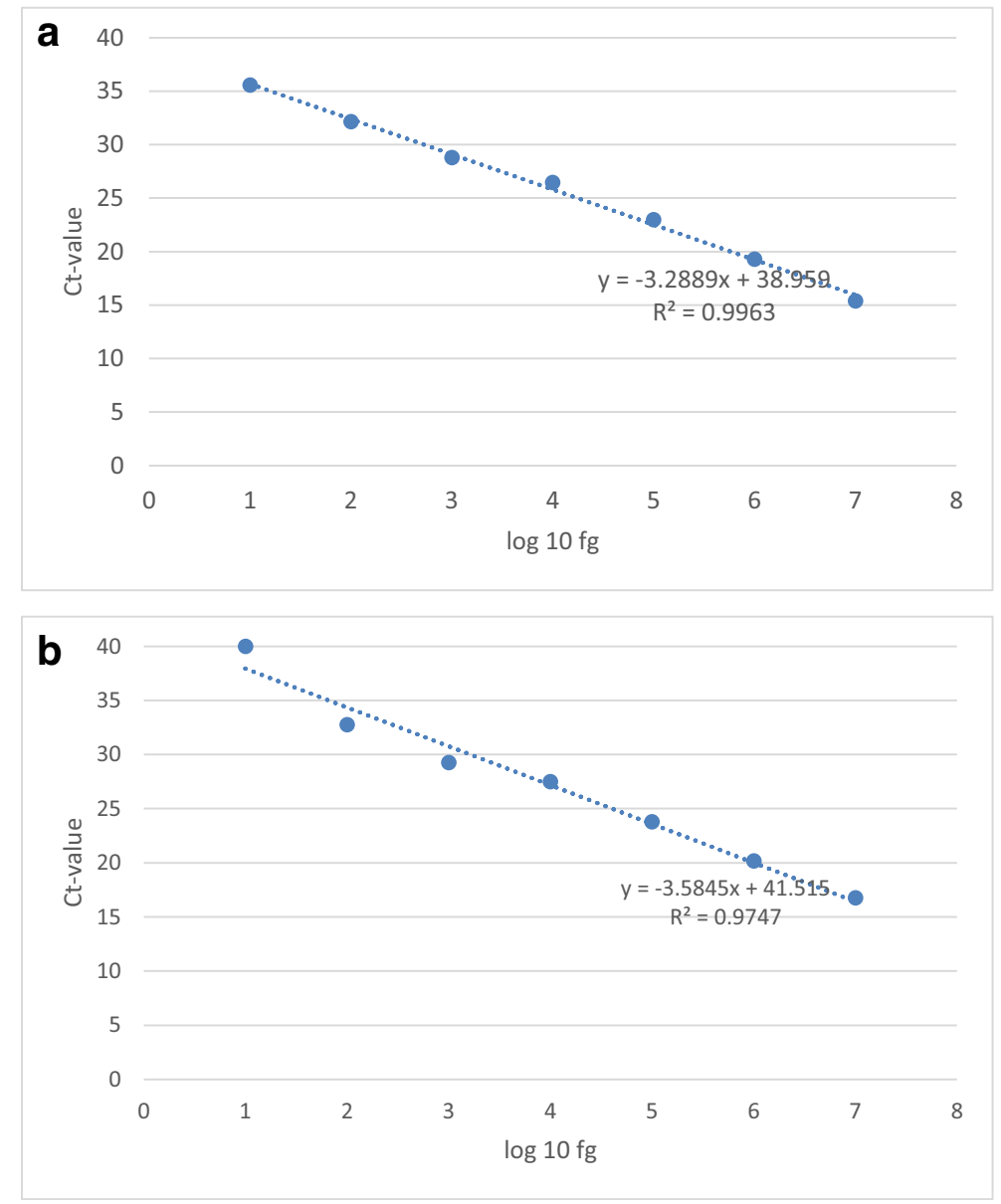

For both TaqMan assays the detection level was $100 \mathrm{fg}$ bacterial DNA per reaction in a background of potato DNA.

This study has shown that two TaqMan assays have been developed that can detect all Dickeya species found on potato. If necessary, samples positive in the generic assays can be further analysed with Dickeya species-specific assays.

Acknowledgements This research was funded by the Dutch Ministry of Economic Affairs, The Dutch General Inspection Service, The Netherlands Inspection Service for Horticulture and The Flower Bulb Certification Agency in the Topsector Program "Horticulture and Starting Materials" under theme "Plant Health" and having the project number 1406-062.

\section{Compliance with ethical standards}

Conflict of interest The authors herewith declare that they have no conflict of interest. This study does not contain studies with human participants or animals performed by any of the authors.
Open Access This article is distributed under the terms of the Creative Commons Attribution 4.0 International License (http:// creativecommons.org/licenses/by/4.0/), which permits unrestricted use, distribution, and reproduction in any medium, provided you give appropriate credit to the original author(s) and the source, provide a link to the Creative Commons license, and indicate if changes were made.

\section{References}

Adeolu M, Alnajar S, Naushad S, S. Gupta R (2016). Genomebased phylogeny and taxonomy of the 'Enterobacteriales': Proposal for Enterobacterales Ord. Nov. divided into the families Enterobacteriaceae, Erwiniaceae fam. Nov., Pectobacteriaceae fam. Nov., Yersiniaceae fam. Nov., Hafniaceae fam. Nov., Morganellaceae fam. Nov., and Budviciaceae fam. Nov. International Journal of Systematic and Evolutionary Microbiology 66: 5575-5599.

Czajkowski, R., Perombelon, M. C. M., van Veen, J. A., \& van der Wolf, J. M. (2011). Control of blackleg and tuber soft rot of potato caused by Pectobacterium and Dickeya species: A review. Plant Pathology, 60, 999-1013. 
Hugouvieux-Cotte-Pattat, N., Jacot-des-Combes, C., \& Briolay, J. (2019). Dickeya lacustris sp. nov., a water-living pectinolytic bacterium isolated from lakes in France. International Journal of Systematic and Evolutionary Microbiology, 69, 721-726.

Kalinina, O., Lebedeva, I., Brown, J., \& Silver, J. (1997). Nanoliter scale PCR with TaqMan detection. Nucleic Acids Research, 25, 1999-2004.

Khayi, S., Blin, P., Chong, T. M., Chan, K. G., \& Faure, D. (2016). Complete genome anatomy of the emerging potato pathogen Dickeya solani type strain IPO 2222. Standards in Genomic Sciences, 11, 87. https://doi.org/10.1186/s40793-016-0208-0.

Li H (2013). Aligning sequence reads, clone sequences and assembly contigs with BWA-MEM. arXiv:1303.3997.

Nassar, A., Darrasse, A., Lemattre, M., Kotoujansky, A., Dervin, C., Vedel, R., \& Bertheau, Y. (1996). Characterization of Erwinia chrysanthemi by pectinolytic isozyme polymorphism and restriction fragment length polymorphism analysis of PCR-amplified fragments of pel genes. Applied and Environmental Microbiology, 62, 2228-2235.

Naushad, H. S., Lee, B., \& Gupta, R. S. (2014). Conserved signature indels and signature proteins as novel tools for understanding microbial phylogeny and systematics: Identification of molecular signatures that are specific for the phytopathogenic genera Dickeya. Pectobacterium and Brenneria. International Journal of Systematic and Evolutionary Microbiology, 64, 366-383.

Parkinson N, De Vos P, Pirhonen M, Elphinstone J (2014). Dickeya aquatica sp. nov., isolated from waterways. International Journal of Systematic and Evolutionary Microbiology, 64, 2264-2266.

Pritchard, L., Humphris, S., Saddler, G. S., Parkinson, N. M., Bertrand, V., Elphinstone, J. G., \& Toth, I. (2013).
Detection of phytopathogens of the genus Dickeya using a PCR primer prediction pipeline for draft bacterial genome sequences. Plant Pathology, 62, 587-596.

Samson, R., Legendre, J. B., Christen, R., Fischer-Le Saux, M., Achouak, W., \& Gardan, L. (2005). Transfer of Pectobacterium chrysanthemi (Burkholder et al.. 1953) Brenner et al.. 1973 and Brenneria paradisiaca to the genus Dickeya gen. nov as Dickeya chrysanthemi comb. nov and Dickeya paradisiaca comb. nov and delineation of four novel species, Dickeya dadantii sp nov., Dickeya dianthicola $\mathrm{sp}$ nov., Dickeya dieffenbachiae sp nov and Dickeya zeae sp nov. International Journal of Systematic and Evolutionary Microbiology, 55, 1415-1427.

Tian, Y., Zhao, Y., Yuan, X., Yi, J., Fan, J., Xu, Z., Hu, B., de Boer, S. H., \& Li, X. (2016). Dickeya fangzhongdai sp. nov., a plant-pathogenic bacterium isolated from pear trees (Pyrus pyrifolia). International Journal of Systematic and Evolutionary Microbiology, 66, 2831-2835.

Toth, I. K., van der Wolf, J. M., Saddler, G., Lojkowska, E., Helias, V., Pirhonen, M., Tsror, L., \& Elphinstone, J. G. (2011). Dickeya species: An emerging problem for potato production in Europe. Plant Pathology, 60, 385-399.

Tsror, L., Erlich, O., Hazanovsky, M., Ben Daniel, B., Zig, U., \& Lebiush, S. (2012). Detection of Dickeya spp. latent infection in potato seed tubers using PCR or ELISA and correlation with disease incidence in commercial field crops under hotclimate conditions. Plant Pathology, 61, 161-168.

Van der Wolf JM, de Haas BH, van Hoof R, de Haan EG, van den Bovenkamp GW (2014). Development and evaluation of Taqman assays for the differentiation of Dickeya (sub)species. European Journal of Plant Pathology, 138, 695-709. 